\title{
Special Support for Behavior Difficulties and Engagement in Swedish Preschools
}

\author{
Lena Almqvist ${ }^{1,2 *}$, Madeleine Sjöman ${ }^{2}$, Marie Golsäter $^{3,4}$ and Mats Granlund ${ }^{3,5}$ \\ ${ }^{1}$ School of Health, Care, and Welfare, Mälardalen University, Västerås, Sweden, ${ }^{2}$ CHILD Research Group, School of \\ Learning and Communication, Jönköping University, Jönköping, Sweden, ${ }^{3}$ CHILD Research Group, School of Health and \\ Welfare, Jönköping University, Jönköping, Sweden, ${ }^{4}$ Futurum Region Jönköping County, Jönköping, Sweden, ${ }^{5}$ Department \\ of Special Education, Oslo University, Os/o, Norway
}

\section{OPEN ACCESS}

Edited by: Anthea Gulliford, University of Nottingham, United Kingdom

Reviewed by:

Darren Hedley,

La Trobe University, Australia Caroline Bond, University of Manchester, United Kingdom

${ }^{*}$ Correspondence: Lena Almqvist lena.almqvist@mdh.se

Specialty section: This article was submitted to Special Educational Needs, a section of the journal Frontiers in Education

Received: 13 October 2017 Accepted: 01 May 2018 Published: 15 May 2018

Citation:

Almqvist L, Sjöman M, Golsäter M and Granlund M (2018) Special Support for Behavior Difficulties and Engagement in Swedish Preschools.

Front. Educ. 3:35.

doi: 10.3389/feduc.2018.00035
The Swedish preschool curriculum stipulates that all children independent of support needs should attend mainstream preschool groups, with equal opportunities for learning and engagement. Preschool teachers are responsible for paying attention to children in need of special support to achieve this. How support is provided for children in need of special support due to behavior difficulties in Swedish preschools varies, however. Some children, often formally identified as in need of special support, are supported by preschool staff supervised by external services. Other children receive support initiated and implemented by preschool staff, without supervision from external services. A further number of children receive no support for behavior difficulties, on top of what is provided to all children. This study investigated associations between support format (i.e., supervised support, staff-initiated support, or no additional support), support content (i.e., implementation of support), behavior difficulties, socio-demographics and engagement. A mixed methods approach was used with a sample of 232 preschool children 15-71 months with assessed behavior difficulties. Preschool staff reported on the children's engagement, behavior difficulties, socio-demographics, and support provision. Logistic regression models were used to analyze the probability of children receiving either support format. Content analysis was used to categorize the support content, reported by preschool staff through open-ended questions. Point-biserial correlations were used to test associations between support content, behavior, socio-demographics and engagement. All children receiving supervised support for behavior difficulties were formally identified by external services as in need of special support. Supervised support was also more common if children disturbed the free play in the preschool group, with the most frequent support being collaboration with external teams. Staff-initiated support was most commonly given to children with high engagement, and for children who are not early second language learners. These children were most frequently supported by staff paying attention to negative behavior. Children who were not perceived as a burden to the group were less likely to receive any form of additional support. Ways of managing the preschool group seem to guide support strategies for children with behavior difficulties, rather than child-focused strategies emphasizing engagement in everyday activities.

Keywords: special support, preschool, behavior difficulties, engagement, support format, support content, supervised support, staff-initiated support 


\section{INTRODUCTION}

The early identification of children in need of special support because of behavior difficulties has long been a major issue, with the rationale that early detection leads to early intervention (Hester et al., 2004; Groark et al., 2011). Still, it is not well known what factors influence the provision of special support, i.e., early intervention, in Swedish preschools. Lillvist and Granlund (2010) found that children formally identified as in need of special support and children supported on the initiative of the staff to a great extent exhibited the same type of functional difficulties, for example peer problems. Even so, how staff implement support and decide upon support content for children with behavior difficulties in preschool probably differs depending on whether the child has been formally identified as in need of special support or not (Granlund and Lillvist, 2015). Knowledge of how children with behavior difficulties are supported in preschool and how support measures are related to positive and important learning outcomes, such as engagement, is lacking. In this study, associations between support format (i.e., supervised support, staff-initiated support or no additional support), support content (i.e., implementation of support strategies), behavior (strengths and difficulties), socio-demographics and engagement, were investigated.

Identification of children's special needs and type of special support varies between different countries. For example, in the US the identification of special needs is related to diagnosis or living in poverty (Farran and Son-Yarbrough, 2001). The most common form of support for children with identified needs is provided by federally funded special preschools, such as Head Start or Title 1 (Farran and Son-Yarbrough, 2001; Green et al., 2014). In European countries the majority of children in the early years attend mainstream preschools regardless of medical diagnoses or risks related to poverty (Taggart et al., 2006; European Agency for Special Needs and Inclusive Education, 2016). Special support is provided within everyday activities (Nutbrown and Clough, 2004; OECD, 2006; Drabble, 2013), and in some countries, for example in the UK, preschools need to show evidence of strategies before referring to external agencies for support (Department for Education/Department of Health, 2015). In Sweden, more than $80 \%$ of all children between 1 and 5 years attend preschool, of which $50 \%$ are children between 1 and 3 years of age (National Agency for Education, 2015). On average, 16 there are around children in each classroom, with a child-teacher ratio of 5:1. A large proportion of the preschool activities are free play (for example activities where children mainly decide the selection of the material and content of the activity). Such self-managed activities place high demands on young children's ability to function in accordance with norms and expectations of how to behave in a social context (Wood, 2013). With age and maturity, most children function well in the preschool context (Swedish National Institute of Public Health, 2009). For some children, the staff however have to provide additional support (Coplan et al., 2001; Björck-Åkesson and Granlund, 2004). The school law (2010:800) stipulates that the preschool should prepare children for continued education and that all children should be provided with support if needed.
The law does however not specify whether this support needs to be provided by experts or if preschool staff can identify and intervene with difficulties without involving experts. No response to treatment model is followed and the preschool staff do not have to prove that they have provided support before asking the preschool manager or parents to involve external experts. The Swedish preschool curriculum advocates an inclusive approach in which all children, with and without support needs, attend mainstream preschool groups, and have equal opportunities for learning and development. The preschool staff are responsible for paying special attention to children in need of special support, and special support is usually provided by adapting the activities to meet their needs (National Agency for Education, 2015). This is often reported to be a challenge, due to limited resources, and an increasing number of children assessed by preschool staff as in need of additional support due to behavior difficulties (Sheridan et al., 2014; Pramling Samuelsson et al., 2015). It is uncertain if the inclusive approach stipulated by Swedish school law is accomplished for all children in need of special support for behavior difficulties (Swedish Schools Inspectorate, 2017b). International research (e.g., Nutbrown and Clough, 2004) reports that support based on professionals' experiences of developing preschool staff attitudes and skills, and involving parents are important. These measures do however require that children are formally identified as in need of special support.

About $4-5 \%$ of the children in Swedish preschools have been formally identified as in need of special support from services external to preschool, based on disability or diagnosis (Lillvist and Granlund, 2010). A relatively large proportion of these children may hold both a diagnosis or show developmental delay, and also show behavior difficulties. Some of these children (about $30-40 \%)$ are provided with supervised support for behavior difficulties (Lillvist and Granlund, 2010). To obtain supervised support from external experts children must be assessed and identified by external support services, for example child health services or child habilitation services (Björck-Åkesson and Granlund, 2004). The assessment procedure is primarily based on norm-referenced measures of skills and/or diagnosis, rather than on everyday functioning in preschool activities (Björck-Åkesson and Granlund, 2004; Lebeer et al., 2010). After an eligibility decision, support under supervision from external experts can be provided. Intervention plans based on this support format, i.e., "supervised support under supervision" (SuS), are usually developed in collaboration between professionals, for example psychologists, or speech therapists, in organizations external to preschool and parents (Björck-Åkesson and Granlund, 2004). Plans frequently focus on skills training. Preschool staff are relatively seldom involved in the decision-making process (Sandberg et al., 2010). They may however implement the intervention plans within the everyday preschool context, under the supervision of the external support services. This skillfocused planning procedure based on norm referenced tests may lead to supervised interventions that are deficit related, for example focusing upon difficulties in talking or attentional deficits, rather than upon functional difficulties in everyday activities in preschool, for example seldom engage in social interaction with other children (Björck-Åkesson and Granlund, 
2004). Interventions for behavior difficulties may not be included in these plans since these cannot be explained by a traditional developmental framework and therefore no specific goals are set that focus on developmentally based goals (Björck-Åkesson and Granlund, 2004; Drabble, 2013). Thus, the supervised support format in preschool for children who are formally identified primarily leads to interventions based on developmentally focused assessment of the child rather than assessment of child functioning in preschool, These interventions might therefore not directly increase the possibilities for children to be engaged and function well in preschool.

An alternative means to identify children in need of special support because of behavior difficulties is to let people that interact with the children in everyday life, for example preschool staff, identify children's need of special support. The school law governs this functional definition of children in need of special support (National Agency for Education, 2010) and states that the preschool should adapt activities to the needs of every child. Documentation of this type of staff-initiated support without supervision ( $\mathrm{SiS}$ ) is not needed, and the law does not state that internal or external experts are required to be involved in implementing the support. Nor does the law state that staff need documented skills or training to implement SiS. Based on preschool staff judgments, an additional 14-15\% of children in Swedish preschools are considered to need special support to function in the everyday activities in preschool (Lillvist and Granlund, 2010). Some of these children display behavior difficulties, for example conduct problems and/or hyperactivity, that affects the child's functioning in the preschool group. These children are sometimes provided with staff-initiated support without supervision from external experts (SiS). The aim of the support is sometimes focused on helping the child to function better in the preschool environment, i.e., to play with peers and participate in developmentally appropriate activities (Sandberg et al., 2009). However, sometimes the aim is mainly to decrease the influence of the child's behavior difficulties on group functioning (Lahdenperä, 1999; Drugli, 2014). SiS is probably the only intervention most children in need of special support receive because of behavior difficulties (Lillvist and Granlund, 2010; Sheridan et al., 2011). The aim of SiS could differ depending on who is identifying support needs and how the support needs are related to the needs of the preschool group.

While the curriculum covers several goals, there is a lack of guidelines for how to organize everyday activities to support children with special needs. The preschool staff are free to interpret curriculum goals and decide how to realize them, a process that is dependent on the staff's didactic skills, knowledge of the preschool curriculum and beliefs and views concerning children (Sheridan et al., 2011). Consequently, not all children in need of special support receive additional support in preschool on top of what is provided to all children (Sandberg et al., 2010). Specific programs or structured approaches to identify children in need of special support are seldom used (Tegenfeldt and Hellgren, 2009) and no registers exist. Thus, data on the provision of special support in preschool due to behavior difficulties is hard to obtain when the definition of special support is based on the support format SiS and provided to children identified only by staff. In this study, it was necessary to include all children in the selected preschools as participants. We then used staff reports on which children that received SuS, SiS or no additional support, as well as cut-off limits of behavior difficulties and impact of behavior difficulties on the preschool group to obtain this information.

It is important to go beyond formal identification and diagnoses when studying special support for children with behavior difficulties in preschool. Still, most research is based on formally identified children, for example children with developmental delay or ADHD. Not all formally identified children display behavior difficulties. Also, the interrelations between different types of behavior difficulties vary over time (Gillberg, 2010). Children can display almost all types of behavior difficulties in different combinations over the preschool years (Keenan et al., 1997; Egger and Angold, 2006). Children's behavior could also be judged as problematic in one context, for example in preschool, but considered unproblematic in another context, for example at home (Gardner and Shaw, 2011). How special support is related to the impact of behavior difficulties on everyday functioning for the child and the preschool group is lacking.

The impact of behavior difficulties on children's everyday functioning differs depending on both child- and environmental characteristics. Children with early behavior difficulties are at risk of more negative social experiences than other children (Plueck et al., 2015). Positive environmental influences can prevent a negative behavioral development. In a Swedish study of preschool children, Sjöman et al. (2016) found that teacher responsiveness and positive peer interaction mediated the negative relationship between children's hyperactive behavior difficulties and engagement. Engagement is manifested by the child's active interaction with the environment in developmentally appropriate manner (Aydogan, 2012; Casey et al., 2012), and is a focused goal in the Swedish preschool curriculum (National Agency for Education, 2010). However, engagement includes a continuum of behaviors from low complexity, for example paying attention to things or staying busy, to high complexity (Raspa et al., 2001), for example symbolic play or persistence in completing an activity. Children show a varied repertoire of engagement behaviors throughout a day, of both high and low complexity, however children with behavior difficulties more typically exhibit engagement behaviors of low complexity. High engagement in behaviors of low complexity combined with difficulties of adjusting to rules and routines and interacting appropriately with peers may challenge the staff's ability to manage the group. According to preschool staff, functional skills such as independence, adjusting to rules and routines, and getting along with peers are more important to learn in preschool than pre-academic skills (Rimm-Kaufman et al., 2000). Staff on their own initiative typically use three different support strategies to support children with behavior difficulties. They either reinforce positive behavior, direct children to appropriate behavior, or reprimand negative behavior (Snell et al., 2012). The use of strategies to reinforce positive behavior in preschool has been related to decreased behavior difficulties and more time spent in engagement behaviors with 
high complexity, for example persistence in finishing activities or engaging in symbolic play (Blair et al., 2010). Whether or not interventions focused on child engagement as a means to promote everyday functioning is an explicit goal of special support for children with behavior problems is not known.

Informal decisions about special support provision for children are probably guided by several factors, such as how the child is perceived to function in relation to peers and staff, staff's attitudes toward norms of behaving and to what degree the child challenges these norms. What is defined as problematic behavior is related to expectations of children's behavior and to the functioning of the preschool group (Raver et al., 2009). Both how staff and other children perceive a child is important. Children with hyperactive behavior who are also engaged and prosocial, and liked by peers, teachers, and others, tend to be perceived as less problematic (Andrade and Tannock, 2013; Sjöman et al., 2016). Probably children who are not perceived as engaged by teachers for any reason, for example through language and cultural differences or passivity, may potentially elicit less teacher responsiveness.

Preschool staff have been reported to lack necessary knowledge of the needs, experiences and interests of minority ethnic children, as well as of their language, and skill levels. Prevalence rates of behavior difficulties in children with other ethnicity have not been reported in the Nordic countries, but international studies suggest that the prevalence of behavior difficulties is higher among minority children (D'Souza et al., 2017). Minority children are also more frequently placed in preschools with many children and low staff ratio (Skalická et al., 2015). In such large groups, difficulties that do not affect other children or the group, for example emotional symptoms or low engagement in preschool activities, might not be recognized. The Swedish Schools Inspectorate (2017a) has found shortcomings in how preschool staff organize everyday activities aiming to develop language and knowledge of children with another ethnicity. Learning and engagement were not emphasized to the same extent as for children with Swedish ethnicity, rather safety and care were prioritized. Lack of awareness of the needs of children with other ethnicity may impact on support decisions, with potentially a higher risk that these children may not be supported for behavior difficulties to the same extent as children with Swedish ethnicity.

Staff can perceive the impact of behavior difficulties as mainly child-focused, for example social exclusion and peer conflicts following from the child's problematic behavior (Cohen and Mendez, 2009). If so, the staff may try to support the child to interact better with peers and to avoid getting in trouble by keeping an extra eye on the child. The impact of behavior difficulties could also be perceived as a contextual problem for the group, for example the child disturbs play, routines or organized activities for the whole preschool group (Drugli, 2014). If so, staff may initiate special support primarily focusing on how to organize activities that enables them to manage the group. How the impact of children's behavior difficulties are perceived by staff probably to a large extent influences how the staff plan, organize, and implement special support within the framework of the preschool curriculum.
In summary, earlier research shows that about $4-5 \%$ of the children in Swedish preschools have been formally identified as in need of special support, however the presence or impact of behavior problems in this group is unclear. An additional $14-15 \%$ of the children have been reported by preschool staff as in need of special support due to functional difficulties, sometimes including behavior problems such as hyperactivity, conduct, or peer problems. As of today, there is still great uncertainty as to how young children are supported for behavior difficulties in Swedish preschools, as well as how engagement influences support provision and support content for these children. Empirical findings suggest that while some children with hyperactive behavior more commonly are less engaged in preschool activities, other children could be very engaged. Sometimes these engagement behaviors of lower complexity are interpreted as conduct problems, especially in child organized activities where no on task activities as intended by staff are identified (e.g., Sjöman et al., 2016). Staff may provide support to these children with the rational to enhance group functioning rather than promoting engagement in individual children. Studies have shown that children with hyperactivity that are prosocial and do not disturb the group are perceived as less challenging for the staff (Andrade and Tannock, 2013; Sjöman et al., 2016). Children with other ethnicity have a higher prevalence of behavior difficulties and are more frequently placed in preschool units with large groups and low staff ratio (Skalická et al., 2015). In these large groups, difficulties not affecting other children or the group may not be recognized. Based on these assumptions, the aim of this study was to investigate associations between support format (i.e., supervised support, teacher-initiated support or no additional support), support content (i.e., implementation of support strategies), behavior (strengths and difficulties), socio-demographics, and engagement.

Specifically, we hypothesized that (1) behavior difficulties perceived to disturb the group lead to support provision by staff (SiS), especially in children that are typically engaged in preschool activities, and (2) other ethnicity, i.e., being an early second language learner, and not being perceived as a burden to the preschool group or staff may lead to no support provision for behavior difficulties in preschool, and (3) the type of support, i.e., support content, provided to children for behavior difficulties in preschool is mainly focused on controlling negative behavior when support is provided on staff initiative. In addition, we investigated how support content is related to behavior difficulties, socio-demographics and child engagement, for children aged 15-71 months.

\section{MATERIALS AND METHODS}

\section{Subjects and Settings}

The data were derived from a subsample from the first measurement point of a longitudinal study about the association between preschool-related factors and children's mental health (Granlund et al., 2015). In the longitudinal study children were followed for two years with three waves of data collection. The convenience sample from the original study was collected in 
31 preschools (92 classrooms) in one large sized municipality ( $>200,000)$, four middle sized (50,000-200,000), and one small municipality $(<50,000)$. In total, 832 children participated in at least one wave, of which 663 children participated in the first wave. Child and demographic characteristics from the sample participating in the first wave are presented in Table $\mathbf{1}$.

The subsample in this study consists of 232 children with behavior difficulties, aged between 15 and 71 months $(m=41, s d$ $=15$ ), participating in the first wave of data collection, from 29 of the preschools (66 classrooms) in the included municipalities from the original sample. The average teacher-child ratio in the participating classrooms were 1:5.4 $(s d=1.5)$, ranging from 2.4 to 9.5 , with an average number of staff of 3.7 On average the classrooms consisted of 23.2 children, ranging from 8 to 50. Classrooms with larger numbers divided the children into smaller groups during the everyday activities in preschool. Of the children in the subsample $12.1 \%$ were formally identified as children in need of special support due to a diagnosis or disability and $31 \%$ were early second language learners of Swedish (EL2), i.e., they are entitled to mother tongue education. Additional child and preschool characteristics from the subsample are presented in Table 1.

The selection criterion of the subsample is based on the preschool staff's estimation of children's behavior difficulties according to the borderline or abnormal categories in the subdimensions of the Strengths and Difficulties Questionnaire (SDQ; Goodman, 1997): emotional symptoms, conduct problems, hyperactivity and peer problems. The abnormal categories are ranged 4-10 (conduct and peer problems), 5-10 (emotional symptoms), and 7-10 (hyperactivity). Children can be classified as borderline in the different subdimensions if they score 3 (conduct and peer problems), 4 (emotional symptoms), or 6 (hyperactivity) (Goodman, 1997). This is just a rough estimation to detect behavior difficulties. Goodman (2001) argues that SDQ ratings should be combined with the SDQ impact supplement scores to provide a more accurate classification. Therefore, we also included children who were classified into the normal range category in all SDQ subdimensions but rated on

TABLE 1 | Demographics and different types of behavior difficulties of the original sample including all children and the subsample.

\begin{tabular}{lrrrrr}
\hline & \multicolumn{2}{c}{$\boldsymbol{n}=\mathbf{6 6 3}$} & & \multicolumn{2}{c}{$\boldsymbol{n = 2 3 2}$} \\
\cline { 2 - 3 } \cline { 6 - 6 } & $\%$ & $\boldsymbol{n}$ & & $\%$ & $\boldsymbol{n}$ \\
\hline Boys & 51.3 & 340 & & 54.7 & 127 \\
EL2 of Swedish & 26.2 & 174 & & 31.0 & 72 \\
Entitled to formal support & 4.8 & 32 & & 12.1 & 28 \\
Hyperactivity & 10.1 & 67 & & 28.9 & 67 \\
Peer problems & 14.5 & 96 & & 41.4 & 96 \\
Emotional problems & 0.2 & 12 & & 5.2 & 12 \\
Conduct problems & 18.2 & 121 & & 52.2 & 121 \\
\hline
\end{tabular}

The number of children in this table with different types of behavior problems does not add to the number of the total sample or the subsample, since some of the children display two or more types of behavior problems. EL2 of Swedish, Children living in a family where at least one parent speaks another language than Swedish. the SDQ impact supplement as having difficulties with emotions, concentration, behavior or socializing with others in preschool. These children were rated by staff not to have specific behavior problems that fully matched the problem categories in the SDQ scale, but to display difficulties that impacted on their everyday functioning in preschool. According to the preschool staff, $31 \%$ of the total sample showed borderline or abnormal problems in at least one of the SDQ subdimensions $(n=203)$ or minor to serious difficulties in one or several of the above-mentioned areas in preschool that impacted on their everyday functioning $(n=29)$. In the subsample, $6.5 \%(n=15)$ received $\mathrm{SuS}, 26.3 \%(n$ $=61)$ received $\mathrm{SiS}$, and $67.2 \%(n=156)$ received no support for behavior difficulties. According to the impact supplement, 50.4\% $(n=117)$ of the children in the subsample showed minor to serious difficulties concerning emotions, concentration, behavior, or getting along and socializing with others in preschool. Thus, to be sure to include all children that could be targeted for special support, the sample included both children rated as having behavior difficulties in one or more SDQ subdimensions as well as those children only rated as having emotional, concentration, behavior or social difficulties related to preschool functioning. Complete data on age and gender was available for all children; data on engagement and behavior difficulties had less than 5\% missing data. Missing data was treated using available-case analysis and pairwise deletion. No outliers were detected.

The proportion of children with different types of behavior difficulties in SuS, SiS and no support categories are presented in Table 2.

\section{Instruments}

The preschool staff provided information about sociodemographics (gender, age, and EL2), and about formal support.

\section{Behavior Difficulties}

The Strengths and Difficulties Questionnaire (SDQ) was used to measure children's behavior difficulties and prosocial skills (Goodman, 1997; Gustafsson et al., 2016). The instrument consists of 25 items with five subscales: emotional symptoms, conduct problems, hyperactivity, peer problems, and prosocial skills, on a three-point Likert scale from 0 to 2: "not at all"

TABLE 2 | Proportion of children with behavior difficulties according to support format (\%).

\begin{tabular}{lcccc}
\hline & $\begin{array}{c}\text { Total } \\
\text { sample } \\
(\boldsymbol{n}=\mathbf{2 3 2})\end{array}$ & $\begin{array}{c}\text { SuS } \\
(\boldsymbol{n}=\mathbf{1 5})\end{array}$ & $\begin{array}{c}\text { SiS } \\
(\boldsymbol{n}=\mathbf{6 1 )}\end{array}$ & $\begin{array}{c}\text { No } \\
\text { support } \\
(\boldsymbol{n}=\mathbf{1 5 6})\end{array}$ \\
\hline Hyperactivity & $67(28.9)$ & $6(40.0)$ & $24(39.3)$ & $40(25.6)$ \\
Emotional problems & $12(5.2)$ & $0(0.0)$ & $2(3.3)$ & $10(6.4)$ \\
Conduct problems & $121(52.2)$ & $7(46.7)$ & $41(67.2)$ & $76(48.7)$ \\
Peer problems & $96(41.4)$ & $7(46.7)$ & $22(36.1)$ & $69(44.2)$ \\
\hline
\end{tabular}

The numbers and percentages do not add up to the number of the total sample, since some children display difficulties in two or more areas. SuS, Supervised Support; SiS, Staff-Initiated Support. 
(0), "only a little" (1), and "quite a lot" (2). The internal consistency in this study for the SDQ subscales was $\alpha=0.58$ for emotional symptoms, $\alpha=0.75$ for conduct problems, $\alpha=0.84$ for hyperactivity, $\alpha=0.69$ for peer problems, and $\alpha=0.84$ for prosocial behavior.

Concurrent validity and reliability of the Swedish version of SDQ has been tested for two age groups (1-3 and 3-5) (Gustafsson et al., 2016). The staff rated the utility of each item in SDQ for both age groups. It was rated good by at least $84 \%$ for all items (Granlund et al., 2015). Validity and reliability were tested with factor analysis and test-retest correlations (Gustafsson et al., 2016). The hyperactivity and conduct problem subscales had good validity and reliability for both age groups, whereas the subscales emotional symptoms and peer problems were not as valid or reliable for children aged 1-3. The emotional symptoms scale and peer problems scale should primarily be used with the older children. In this study, the children often displayed more than one type of behavior difficulty. For this reason, we used all the subscales, but were careful with drawing specific conclusions based solely on problem categories.

The SDQ includes an impact supplement, designed to measure whether the child has (1) minor difficulties, (2) clear difficulties, or (3) serious difficulties concerning emotions, concentration, behavior, or getting along with and socializing with others in preschool. The staff were instructed to only respond to questions in the impact supplement if they had scored that the child had at least minor difficulties. The impact supplement includes the questions "How long has the child suffered from these difficulties?" ( 1 = less than 1 month, $2=$ 1-5 months, $3=6-12$ months, and $4=$ more than 1 year), "Does the child worry or suffer from the difficulties?", "Is the child's difficulties a burden to you or the preschool group as a whole?" "Do the difficulties upset or distress the child?" "Do the difficulties interfere with peer relationships?," and "Do the difficulties interfere with classroom learning?", each with scales $1=$ not at all to $4=$ a great deal. Although relevant questions, we decided to adapt the supplement to a Swedish preschool context where commonly a day in preschool consists of three major types of activities. Thus the two last items were replaced with the three items "Do the difficulties interfere with free play?," "Do the difficulties interfere with organized activities?" and "Do the difficulties interfere with routines?" The SDQ impact supplement for 1-5-year olds have good validity and reliability (Gustafsson et al., 2016).

Finally, the preschool staff were asked whether or not the child received special support: (a) supervised support from external support service teams ( $\mathrm{SuS}$ ) or (b) special support initiated by the preschool staff without supervision from external support teams (SiS). Through an open-ended question, the staff were asked to describe the type of support provided, i.e., support content.

\section{Child Engagement}

Children's engagement was measured using the Child Engagement Questionnaire (CEQ; McWilliam, 1991). The original questionnaire, consisting of 32 items with a four-point scale from $1=$ not at all typical to $4=$ very typical, rates global engagement level when the child engages in interaction with peers, adults, materials, and objects in the preschool environment. Thus, the content of items is supposed to measure how typically quality aspects of engagement behavior are exhibited, for example engagement behaviors with higher complexity such as persistence and symbolic play or engagement behaviors of lower complexity such as staying busy or trying to get adults to repeat things. "Typical" means that the child shows this kind of behavior quite often (de Kruif and McWilliam, 1999). To better fit the Swedish preschool context only 30 of the 32 original items were used in this study. The two items that were excluded were "Plays with objects in a single manner (for example repetitive or unchanging)" and "Continues repetitive movements to make sounds with an object." These items represent behaviors that are more typical in children younger than one year or in children with social communication difficulties. Previous analyses conducted in our research group have shown that the inclusion of these two items significantly decrease the internal consistency of the scale, when used in a Swedish preschool context. Children in Sweden do not attend preschool before one year old. Although there may be children within this sample with social communication difficulties, the staff may find it difficult to understand and rate the children's engagement in these behaviors. The two items were thus excluded in this study. The internal consistency of the CEQ in this study was $\alpha=0.96$. The shortened version of CEQ has shown good content and construct validity, as well as intra-rater reliability, in earlier Swedish studies of preschool children (Almqvist, 2006; Sjöman et al., 2016).

\section{Procedure}

The manager of each preschool unit provided classroom-specific information, such as number of children, number of children formally identified as in need of special support, number of children entitled to support in their mother tongue (EL2), type of classroom (for example aged 1-3 or 1-5), and number of staff. After receiving written consent from parents (including consent from parents supported by staff or interpreters for understanding the information), the researchers distributed the questionnaires to the preschool staff in each classroom. Within a period of about 4 weeks, the staff responded and the questionnaires were collected. This study was carried out in accordance with the recommendations of the Swedish Research Council (2017) and was approved by the ethics vetting board in Linköping, Sweden (Dnr 2012/199-31).

\section{Data Analysis}

A mixed-methods parallel design was used to broaden the knowledge of the relationships between support provided and child- and environmental factors that might have an impact on support provision (Teddlie and Tashakkori, 2012). The design included three phases to address each of the research questions: (Phase 1) quantitative analyses of predictors of support format, (Phase 2) qualitative data categorization of support content, and (Phase 3) mixed analyses of the associations between support format, support content and child- and environmental factors.

Complete data on age and gender were available among the subsample of 232 children. Data on engagement and behavior 
difficulties had less than 5 percent missing data, thus imputation of missing values was conducted by available-case analysis and pairwise deletion.

\section{Phase 1: Predictors of Support Format}

Point-biserial correlations $\left(r_{b}\right)$ were used to analyze bivariate relationships between the predictors and support format. Separate logistic regression models were used to analyze which factors predicted SiS or no support in preschool. Predictors entered into the models were based on theoretical assumptions as well as on the point-biserial correlations. Due to limited power, no logistic regression model could be conducted to analyze predictors for the support format SuS. Thus, to study associations between SuS and child and environmental predictors we relied mainly on point-biserial correlations.

\section{Phase 2: Support Content}

To describe the type of support children with behavior difficulties received, the responses on the open questions about support content were subjected to content analysis according to Elo and Kyngäs (2008). In the first step two of the researchers separately read the text from the open questions several times to obtain an overview of the types of support given to the children. In the second step, the researchers separately coded each support content units and grouped them into preliminary categories and then subcategories. Next, the two researchers reviewed each other's codes and categories and discussed them until agreement was reached. Finally, the researchers in collaboration abstracted the preliminary categories into four categories of support content (Table 7).

\section{Phase 3: Support Content in Relation to Support Format, Engagement and Socio-Demographics}

To synthesize the analysis, we first used chi-square analyses to explore the frequency distribution of support content in the two different support formats, SuS and SiS (Table 8). Secondly, we used point-biserial correlations $\left(r_{b}\right)$ to analyze the associations between support format, support content and sociodemographics, behavior (strengths and difficulties), the impact of behavior difficulties, and engagement.

\section{RESULTS}

We investigated (1) how behavior, socio-demographic factors and engagement predict support format, and (2) what type of support, i.e.support content, is provided to children for behavior difficulties in preschool, and (3) how support content is related to support format, behavior, socio-demographics, and child engagement, for children aged 15-71 months.

\section{Predictors of Support Format}

The subsample was categorized into three groups, based on staff reports: (1) children who receive supervised support (SuS) (2) children who receive teacher-initiated special support ( $\mathrm{SiS}$ ), and (3) children who receive no additional support for behavior difficulties. Initial bivariate analyses were conducted to study associations between support format and socio-demographic factors, behavior difficulties, and engagement (Tables 3 and 4). A univariate analysis was conducted for comparisons of the level of behavior difficulties among children in the support format groups (Table 3). These initial analyses showed that hyperactive behavior was negatively related to the no support format group, i.e., this group had significantly lower ratings in hyperactivity than both the SuS format group and the SiS format group. However, conduct problems were related both to the no support format and to the SiS format, although the SiS group had the highest mean ratings.

The logistic regression models were based on theoretical assumptions and from the results of the point-biserial analyses in that only variables that were significantly associated with support format were retained. The analyses were performed to assess the impact of the following variables on the likelihood that the child received SiS or no support for behavior difficulties: SDQ impact supplement variables (for example burden to the group or the teacher, the child worry or suffer of the behavior difficulties, interfere with peer relationship, or classroom learning), the degree of behavior difficulties in each subdimension, degree of prosocial behavior, degree of engagement, age, gender, and being an early second language learner (EL2).

\section{Supervised Support (SuS)}

The most obvious predictor for receiving SuS was to be formally identified by external services as a child in need of special support. All children receiving this support format were formally identified as children in need of special support, $X_{(1, n=115)}^{2}$ $=56.22, p<0.001$, obs $=15$, $\exp =3.5$, Cramer's $\mathrm{V}=$ 0.70 and $\mathrm{OR}=8.33,95 \% \mathrm{CI}[4.90-14.17]$ indicating a large effect. Further, a significant association was found between SuS and "disturbs free play," $r_{b}=0.21, p=0.05$, i.e., children who

TABLE 3 | Pearson correlations and comparison of behavior difficulties on support format.

\begin{tabular}{|c|c|c|c|c|c|c|c|c|c|c|}
\hline & \multicolumn{3}{|c|}{ No support $(n=156)$} & \multicolumn{3}{|c|}{ SuS $(n=15)$} & \multicolumn{3}{|c|}{$\operatorname{SiS}(n=61)$} & \multirow[t]{2}{*}{$\boldsymbol{F}$} \\
\hline & $r$ & $m$ & sd & $r$ & $m$ & sd & $r$ & $m$ & sd & \\
\hline Emotional problems & 0.08 & 0.29 & 0.36 & -0.16 & 0.11 & 0.20 & -0.08 & 0.24 & 0.33 & 1.92 \\
\hline Conduct problems & $0.22^{\star \star}$ & 0.52 & 0.45 & -0.06 & 0.58 & 0.60 & $0.26^{\star \star}$ & 0.76 & 0.46 & $5.55^{\star}$ \\
\hline Hyperactivity & $-0.29^{\star \star}$ & $0.70^{a}$ & 0.56 & -0.03 & $1.07^{b}$ & 0.64 & $0.23^{\star}$ & $1.06^{b}$ & 0.53 & $10.16^{\star \star}$ \\
\hline Peer problems & 0.06 & 0.58 & 0.45 & -0.14 & 0.77 & 0.60 & 0.03 & 0.57 & 0.43 & 3.38 \\
\hline
\end{tabular}

${ }^{\star} p<0.05,{ }^{* *} p<0.01$. The SDQ Subdimension scales are rated from 0 to 2 .

Superscripts $a$ and $b$ indicate significant differences in group means, according to Tukey's post hoc test 
disturbed free play received SuS to a higher degree, and vice versa.

Receiving SuS had the strongest associations with "disturbing free play" and "is a burden to the teacher or preschool group" (Table 4).

\section{Staff-Initiated Support (SiS)}

Fewer children than expected were entitled to support in their mother tongue (EL2) within the group of children who received SiS $(19.7 \%), X^{2}{ }_{(1, n=116)}=10.01, p<0.001$, obs $=12$, exp $=20.0$, Cramer's $\mathrm{V}=0.29$ and $\mathrm{OR}=0.42$, 95\% CI $[0.23-$ 0.74 ], indicating a medium effect size. Conduct problems and hyperactivity were both positively associated with the provision of SiS (Table 3). Child engagement was positively associated with receiving, i.e., children with behavior difficulties who also more typically showed quality engagement in everyday activities in preschool more commonly received SiS (Table 4).

A logistic regression model (Table 5) assessed the impact of four independent variables (degree of conduct problems, being a burden to the preschool staff or group, EL2, child engagement) on the likelihood of SiS. This model provided the best goodness of fit and was statistically significant, $X_{(4, n=82)}^{2}=23.93, p$ $<0.01$. In total, the model explained between $19.7 \%$ (Cox and Snell $R^{2}$ ) and $26.4 \%$ (Nagelkerke $R^{2}$ ) of the variance in SiS. The highest probability of receiving SiS was no EL2 of Swedish, followed by high engagement. Thus, children who more typically showed quality engagement and who were not entitled EL2 of Swedish were more than twice as likely to receive SiS for behavior difficulties in preschool. The hypothesis, stating a significant probability for children with behavior difficulties perceived as a burden to the preschool group or staff and being typically engaged in preschool activities, to receive SiS was confirmed in this study.

\section{No Support}

Conduct problems and hyperactivity were related to no support (Table 3). Being a burden to the group was negatively associated with receiving no support, i.e., children with behavior difficulties who were not perceived as a burden to the group were less likely to receive support for their difficulties (Table 4).

TABLE 4 | Pearson correlations between support format, impact supplement variables, and engagement.

\begin{tabular}{lccc}
\hline & $\begin{array}{c}\text { No } \\
\text { support } \\
(\boldsymbol{n}-\mathbf{1 5 6})\end{array}$ & $\begin{array}{c}\text { SuS } \\
(\boldsymbol{n}-\mathbf{1 5 )}\end{array}$ & $\begin{array}{c}\text { SiS } \\
(\boldsymbol{n}-\mathbf{6 1 )}\end{array}$ \\
\hline Child worries or suffers & 0.07 & 0.03 & 0.14 \\
Disturb free play & 0.08 & $0.21^{*}$ & 0.05 \\
Disturb org situations & 0.06 & 0.05 & 0.06 \\
Disturb routines & 0.12 & 0.13 & 0.13 \\
A burden to teacher or group & $-0.19^{*}$ & $0.32^{\star *}$ & 0.18 \\
Child engagement & 0.06 & -0.11 & $0.30^{\star *}$ \\
\hline${ }^{*} p<0.05,{ }^{* *} p<0.01$. & & &
\end{tabular}

A logistic regression model (Table 6) was performed to analyze the impact of four independent variables: EL2 in Swedish, degree of prosocial skills, degree of hyperactivity, and being a burden to the preschool staff or the group, on the likelihood that children do not receive additional support for behavior difficulties in preschool. A model containing these four predictors provided the best goodness of fit and was statistically significant, $X^{2}(5, n=116)=15.83, p=0.003$.

The model explained as whole between 12.8\% (Cox and Snell $R^{2}$ ) and $26.6 \%$ (Nagelkerke $R^{2}$ ) of the variance. The most significant probability for not receiving support at all was not being a burden to the staff or group. No support for behavior difficulties in preschool was more than twice as likely for children not perceived as a burden to peers or teacher. Prosocial behavior also decreased the likelihood for a child to receive special support in preschool for behavior difficulties. The association for EL2 in Swedish was not significant, although the model revealed a high OR for no support for behavior difficulties. The hypothesis stating a significant probability that children with other ethnicity who are not perceived as a burden receive no support for behavior difficulties was only partly confirmed in this study.

\section{Support Content}

The analysis of the support content revealed four types of support given by the preschool staff (Table 7): Adaptation of

TABLE 5 | Logistic regression model assessing the probability of receiving SiS.

\begin{tabular}{|c|c|c|c|c|c|c|c|c|}
\hline & \multirow[t]{2}{*}{ B } & \multirow[t]{2}{*}{ S.E. } & \multirow[t]{2}{*}{ Wald } & \multirow[t]{2}{*}{$d f$} & \multirow[t]{2}{*}{$p$} & \multirow[t]{2}{*}{ OR } & \multicolumn{2}{|c|}{$95 \% \mathrm{Cl}$} \\
\hline & & & & & & & Lower & Upper \\
\hline Conduct problems & 0.15 & 0.10 & 2.34 & 1 & 0.13 & 1.16 & 0.96 & 1.41 \\
\hline $\begin{array}{l}\text { Burden to teacher/ } \\
\text { group }\end{array}$ & 0.51 & 0.35 & 2.13 & 1 & 0.14 & 1.66 & 0.84 & 3.29 \\
\hline Child engagement & 0.88 & 0.38 & 5.22 & 1 & 0.02 & 2.40 & 1.13 & 5.08 \\
\hline EL2 in Swedish & -1.01 & 0.47 & 4.64 & 1 & 0.03 & 2.76 & 0.1 .10 & 6.94 \\
\hline Constant & -3.40 & 1.34 & 6.44 & 1 & 0.01 & 0.03 & & \\
\hline
\end{tabular}

SDQ Conduct problems scale is reversed, higher ratings represent greater difficulties. EL2 in Swedish is dummy coded: $1=$ yes, $0=$ no.

TABLE 6 | Logistic regression model assessing the probability of receiving no support.

\begin{tabular}{|c|c|c|c|c|c|c|c|c|}
\hline & \multirow[t]{2}{*}{ B } & \multirow[t]{2}{*}{ S.E. } & \multirow[t]{2}{*}{ Wald } & \multirow[t]{2}{*}{$d f$} & \multirow[t]{2}{*}{$p$} & \multirow[t]{2}{*}{ OR } & \multicolumn{2}{|c|}{$95 \% \mathrm{Cl}$} \\
\hline & & & & & & & Lower & Upper \\
\hline $\begin{array}{l}\text { EL2 in } \\
\text { Swedish }\end{array}$ & 0.83 & 0.44 & 3.52 & 1 & 0.06 & 2.29 & 0.96 & 5.44 \\
\hline $\begin{array}{l}\text { Prosocial } \\
\text { behavior }\end{array}$ & 0.16 & 0.08 & 3.90 & 1 & 0.05 & 1.17 & 1.00 & 1.37 \\
\hline Hyperactivity & -0.06 & 0.08 & 0.53 & 1 & 0.47 & 1.06 & 0.90 & 1.25 \\
\hline $\begin{array}{l}\text { Burden to } \\
\text { teacher/ } \\
\text { group }\end{array}$ & -0.76 & 0.34 & 4.94 & 1 & 0.03 & 2.13 & 1.09 & 4.14 \\
\hline Constant & -4.37 & 1.24 & 12.42 & 1 & 0.00 & 0.01 & & \\
\hline
\end{tabular}

$S D Q$ Hyperactivity scale is reversed, higher ratings represent greater difficulties. EL2 in Swedish is dummy coded: $1=$ yes, $0=$ no. 
TABLE 7 | Content analysis of open-ended questions of the SDQ impact supplement.

\section{Examples of answers of the open-ended questions}

We divide the child group as much as we can. Thinking that there should be plenty of space around the child in need of support.

We try to limit visual impression in the classroom. We reduce transitions between activities in order to minimize breakups.

We support the child in play with other children in order to guide in social interactions in preschool.

We give extra attention toward the child. We reinforce and confirm the child's positive behavior.

We use sign language as support in order to refer what we are doing

We have a continuous dialogue and contact with the child's parents.

We discuss within the preschool team about how we treat and handle the child in the classroom.

We have contact with a special educator who occasionally visits us to follow the child's development and provids suggestions for appropriate special support we can use in the classroom.

We give a little extra attention to the social interaction, mainly during free play when the child might be hitting other children when we do not see.

When he is tired, one adult is nearby to him because he often pulls other children at such times.

We try to distract the child by giving him various assignments, such as setting the table or retrieving or returning food carts in the kitchen.

\section{Subcategories}

Adaptation of physical environment

Adaptation of psychosocial environment

Support in play activities

Teacher responsiveness to child

Language support

Collaboration with parents

Collaboration with colleagues

Collaboration with external teams

Attention to critical situatio

Special attention to negative behavior
Individual support

Main categories

Adaptation of preschool environment

Collaboration

Attention by proximity

Distraction from negative behavior

preschool environment, Individual support, Collaboration, and Special attention to children's negative behavior.

Support was given by adapting the preschool environment. The staff tried to support the child by adapting the physical environment, for example dividing the group into smaller units where, one group played outdoors and the other group played indoors to provide space for the child in need of special support. To adapt the psychosocial environment, the staff prepared the child for new activities to facilitate transitions, for example by explicitly going through the routines and describing the planned activity.

The staff supported children individually by being responsive and confirming children's positive behavior, and by actively supporting the child in play activities with other children. The staff also mentioned language support, through both signing and specific training in Swedish, as a way of supporting children individually. Further, the staff supported children by collaborating with parents, colleagues and external teams, for example through regular discussions with parents and within the staff group to assess the child's needs.

Finally, support was provided to the child through special attention to the child's negative behavior. This was primarily implemented by at least one member of the staff staying close to the child. The content of the two subcategories paying attention to critical situations and attention by proximity entailed support by having one staff member nearby to prevent the child from pushing and interfering with the other children in an unfriendly way. The most common way of providing special attention was distracting the child from situations that could trigger negative behavior.

\section{Associations Between Support Content, Support Format, Impact of Behavior Difficulties, Engagement and Socio-Demographics}

Point-biserial correlations showed significant positive associations between psychosocial adaptation and a child's worrying or suffering due to difficulties, $r_{b}=0.27, p=0.029$. Generally, individual support was frequently provided to children who had exhibited difficulties for a short time $\left(r_{b}=\right.$ $-0.31, p=0.012$ ), while collaboration with external teams (supervision) was most common when difficulties had been present for a longer time $\left(r_{b}=0.31, p=0.013\right)$. Support in play activities was most commonly given to children with emotional symptoms $\left(r_{b}=0.31, p=0.012\right)$ or peer problems $\left(r_{b}=0.26\right.$, $p=0.037)$, while children with conduct problems more often were supported by distraction $\left(r_{b}=0.38, p<0.001\right)$. Distraction was also a common strategy if children showed high levels of engagement, $\left(r_{b}=0.43, p<0.001\right)$, or if they worried or suffered due to their difficulties $\left(r_{b}=0.38, p=0.002\right)$. Teacher responsiveness was the most frequent support content if the difficulties were not perceived as a burden to the teacher or the group $\left(r_{b}=-0.30, p=0.016\right)$.

A chi-square test for independence (with Yates Continuity Correction) was conducted to analyze the distribution of support content in relation to the two support formats, i.e., SuS, SiS (Table 8). For both formats, common content was to direct special attention to the child with behavior difficulties. For children receiving SuS, the preschool staff mostly stayed close to the child. They also collaborated to a higher extent with other services, especially external teams. Collaboration with external teams was described more often than expected by 
TABLE 8 | Support content for each support format (major categories in bold).

\begin{tabular}{lcc}
\hline & $\begin{array}{c}\text { SuS } \\
(\boldsymbol{n}=\mathbf{1 5})\end{array}$ & $\begin{array}{c}\text { SiS } \\
(\boldsymbol{n}=\mathbf{6 1})\end{array}$ \\
\hline Adaptation of preschool environment & $\mathbf{3}$ & $\mathbf{1 6}$ \\
Adaptation of physical environment & 1 & 6 \\
Adaptation of psychosocial environment & 2 & 10 \\
Individual support & $\mathbf{3}^{\mathbf{a}}$ & $\mathbf{2 4}$ \\
Support in play activities & 0 & 7 \\
Teacher responsiveness to child & 1 & 10 \\
Language support & 2 & 8 \\
Collaboration & $\mathbf{8}^{\mathbf{b}}$ & $\mathbf{6}^{\mathbf{a}}$ \\
Collaboration with parents & 1 & 2 \\
Collaboration with colleagues & 0 & 2 \\
Collaboration with external teams & $8^{\mathrm{b}}$ & $2^{\mathrm{a}}$ \\
Special attention to negative behavior & $\mathbf{1 0}$ & $\mathbf{3 5}^{\mathbf{a}}$ \\
Attention to critical situations & 1 & 2 \\
Attention by proximity & 6 & 2 \\
Distraction from negative behavior & 4 & 17 \\
\hline
\end{tabular}

a Significantly less frequently described than expected (Chi').

${ }^{b}$ Significantly more frequently described than expected $\left(\mathrm{Chi}^{2}\right)$.

chance, $X_{(1, n=66)}^{2}=26.62, p=0.001$, obs $=7, \exp =1.6$, Cramer's $\mathrm{V}=0.63$, indicating a large effect. Individual support, for example language support, was reported less frequently than expected for children receiving SuS, $X^{2}{ }_{(1, n=2)}=4.97, p=$ 0.034 , obs $=2, \exp =5.7$, Cramer's $\mathrm{V}=0.27, \mathrm{OR}=1.58,95 \%$ CI [1.15-2.17], indicating a medium effect size. Collaboration with external teams occurred less frequently than expected for children receiving $\mathrm{SiS}, X^{2}{ }_{(1, n=2)}=20.34, p=0.001$, obs $=$ 2 , $\exp =5.3$, Cramer's $\mathrm{V}=0.57, \mathrm{OR}=2.25,95 \% \mathrm{CI}[0.95-$ 5.30], indicating a large effect. When SiS was provided, the most common support content was to pay attention to negative behavior $(n=35)$, although this strategy was not reported to be used significantly more frequently than expected by chance. Thus, the hypothesis stated that support content focusing on controlling negative behavior of children receiving SiS was not statistically confirmed.

\section{DISCUSSION}

In this study, we investigated what determines whether or not children with behavior difficulties are provided special support in preschool, and if so, which support format (SiS, SuS, or no additional support) they receive. We also explored the content of the support and its association to child and environmental prerequisites and support format.

In line with previous research (Lillvist and Granlund, 2010), this study revealed that few children receive SuS in Swedish preschools. Only 15 children received SuS due to behavior difficulties and these children were all formally identified as in need of special support by external services. The Swedish school law (National Agency for Education, 2010) does not refer to eligibility criteria for children to be supported in preschool. However, the fact that all the children in this study who receive SuS were also formally identified indicates that such a prerequisite does exist, perhaps because other laws than the school law regulate external services provision such as habilitation or child psychiatric interventions. Such services are regulated by laws based on formal eligibility criteria and referral (National Agency for Education, 2010). Accordingly, the availability of SuS in preschool for behavior difficulties seems at present to be limited to children who are identified as in need of special support, although the needs for identification are not necessarily based on behavior difficulties.

SuS focusing on support in play activities was uncommon and the support was rarely individualized. The children receiving $\mathrm{SuS}$ to a higher extent were perceived to disturb the free play in preschool and collaboration with external teams was the most common support content, especially if difficulties had been present for a longer time. The difficulties these children display are probably more complex with behavior difficulties linked to developmental delay, impairments or specific diagnoses. The support is usually planned outside the preschool context, emphasizing developmental sequences rather than promoting engagement or improving involvement in free-play activities (Björck-Åkesson and Granlund, 2004). Collaboration promotes support over several natural living contexts, but if solely external experts and parents plan support, it might be delimited to a focus on children's abilities or deficits and thus lack an emphasis on how to promote the child's functioning and engagement in the preschool context.

The likelihood of receiving SiS increased if children exhibited high levels of engagement. Children with behavior difficulties who are very engaged may be more visible to the staff as opposed to children who display low engagement. Studies have shown that teachers tend to be more responsive toward children with behavior difficulties who also are engaged in various preschool activities (Sjöman et al., 2016), and thus be more sensitive to these children's need for support. Our initial hypothesis was that children that were perceived as a burden to the staff or group and exhibited a high level of engagement to a higher extent would receive staff-initiated support was partly confirmed. The results indicate that the engagement of these children may lead to social exclusion or peer conflicts (Cohen and Mendez, 2009). Thus, the staff may support them to interact better with peers and avoid trouble, by keeping an eye on the children's behavior. This managing role of the staff might be elicited by children's negative behavior to peers rather than low engagement in learning or positive social interaction with peers. The focus might be more on adult management of learning than on promoting peer interaction.

Support provided to children with externalizing behavior difficulties is probably at least partly based on staff concerns for other children. The majority of children receiving SiS displayed externalizing behavior difficulties, such as conduct problems or hyperactivity. The staff indicated that teacher responsiveness to children's needs, as a support strategy, was less common when the child was perceived as a burden to the group or preschool staff. Earlier studies indicate that preschool staff assesses a child as being in need of special support, when they perceive the child as difficult to interact with (Lahdenperä, 1999). Staying close to 
children displaying externalizing behavior difficulties could be a means to prevent negative impact on classroom functioning and to maintain balance in the group, rather than a support strategy with the goal to promote positive engagement (Drugli, 2014). Such preventive strategies do not require extensive planning and could be adjusted to fit the current group context.

Especially for children receiving SiS, the most common support content was to pay attention to the child's negative behavior or stay close to the child to prevent conflicts, thus confirming the initial hypothesis. Attendance to positive behaviors, such as engagement in activities, was not mentioned as a way of supporting children for behavior difficulties, despite evidence showing that approving behavior in the classroom is related to increased cognitive self-regulation skills and decreased levels of behavior difficulties (Fuhs et al., 2013; Spivak and Farran, 2016). How preschool staff define children in need of special support varies dependent on how behavior difficulties are managed, which in turn is dependent on how staff perceive the origin of the difficulties (Lebeer et al., 2010; Lillvist and Granlund, 2010). If the staff perceive difficulties as mainly linked to child characteristics they might use more individualized support strategies, for example staying close to the child and attend to behavior that is not contextually adaptive (Drugli, 2014). This focus may actually reinforce negative behavior as a means for gaining and maintaining attention from staff. On the other hand, if staff perceive difficulties as mainly context-based they might implement support strategies that emphasize functioning in the preschool group, for example adapt the physical or psychosocial environment (Sandberg et al., 2010). The support content may then be more dependent on the staff's perceptions of and ability to manage children with behavior difficulties than the children's needs per se.

SiS seems to be an internal affair that does not involve collaboration with parents. Collaboration requires that staff formally identify a child as a "problem," which can evoke worries as well as emotionally demanding discussions with parents (Svensson and Janson, 2008). It is likely that the staff will discuss strategies for supporting children with behavior difficulties extensively before involving the parents. Keeping the problem an "internal affair" may however generate narrow solutions focusing primarily on the child, and may not generate effects also outside preschool, for example in families. Several studies in early intervention, for example Dunst et al. (2007) report that when professionals work in a family centered way, involving parents in decision making and intervention planning, it has positive effects not only on the children but also on the wellbeing of parents.

Both earlier studies and the results from this study show that reasons for receiving support or not vary extensively (Sandberg et al., 2010) due to both support format and child characteristics. In this study, the likelihood of receiving SiS was larger if children were not entitled EL2 in Swedish. This may reflect a structural mechanism in Swedish preschools, in that preschools in certain neighborhoods have a high proportion of children with ethnicity other than Swedish, while those in other neighborhoods have mainly children with Swedish ethnicity (Bjurek et al., 1996; Skalická et al., 2015). If the majority of the children are of another ethnicity, staff may not focus on individual children's needs but rather perceive behavior difficulties as temporal, based on language difficulties or adjustment problems due to their background (Gillberg, 2010; Andrade and Tannock, 2013; Swedish Schools Inspectorate, 2017a). The initial difficulties are perceived to decrease over time (Campbell et al., 2000). It is presumable that in preschool groups with only one or a few children in need of special support and/or other ethnicity than Swedish, staff may to a greater extent initiate support if behavior difficulties are present.

The majority of children with behavior difficulties in this study did not receive additional support above what is provided to all children. Our initial hypothesis that being entitled to EL2 in Swedish is a significant predictor for no support for behavior difficulties in preschool was not confirmed, albeit a high odds ratio value. The largest probabilities of not receiving special support for behavior difficulties was not to be perceived as a burden to the staff or preschool group and to display high ratings in prosocial behavior. This indicates a staff perception of children's behavior difficulties as a contextual problem (Drugli, 2014). Thus, if children with behavior difficulties otherwise are not perceived as a burden, for example by requiring a high amount of staff time and resources, and are nice to peers and staff, the likelihood of receiving special support decreases.

\section{Limitations}

The study has several limitations that need to be considered. The sample size was modest, especially concerning children who receive SuS, which limited our possibilities to conduct appropriate statistical tests for this group. The children receiving $\mathrm{SuS}$ were also a heterogeneous group in terms of difficulties and support needs. This limits our ability to draw conclusions as to the rationale for teacher assessments of the support format and support content provided to these children. It is especially important to notice that there may be considerable variability in assessments of special support needs and in interpretation of curriculum goals among preschool staff, not fully captured in this study. Whereas a child with behavior difficulties could be perceived as a burden by one group or staff, in other contexts or by other staff they may not. This may reflect that the staff's assessments of the children's behavior difficulties were not entirely coherent. Some of the children were rated as having behavior difficulties according to one or several subdimension in the SDQ scale, but as not even having minor difficulties in any of the areas listed in the SDQ impact supplement. Children rated as having difficulties in several areas according to the SDQ impact supplement were not always rated as having behavior difficulties according to the SDQ scale. This can question how useful SDQ is to capture behavior difficulties of young children. However, concurrent validity and reliability of SDQ has been tested for 1-3year-olds as well as for 3-5-year-olds (Gustafsson et al., 2016) and utility assessment have been considered good (Granlund et al., 2015). More knowledge is needed in how behavior difficulties are related to how teachers perceive the impact on everyday functioning in preschool and special support.

Despite these limitations, important implications can be derived from our findings. The majority of children in preschool 
are not supported for behavior difficulties, especially when they do not disturb group functioning. This study showed a tendency that children entitled to EL2 less frequently receive additional support for behavior difficulties on top of what is provided to all children. This result, however, has to be confirmed in a larger-scale study, preferably investigating reasons for special support exclusion. Only children formally identified as in need of special support receive SuS. Children who do disturb group functioning and are very engaged more commonly receive SiS. The most common way of supporting children is by paying special attention to prevent them getting into trouble. Higher levels of engagement in developmentally appropriate activities are rarely mentioned as a goal for support. Rather, preschool staff tend to initiate special support for children's behavior difficulties based on an estimation of the functional impact on child and/or group functioning rather than on children's behavior difficulties per se. More child-focused strategies concerning how to promote engagement in everyday activities are needed. This need indicates that preschool staff need to be more involved in providing SuS (Nutbrown and Clough, 2004) as well as receiving continuing professional development in providing SiS, as suggested by Poulou and Norwich (2000). It is also important to consider how parents can be involved to a larger extent when SiS is provided (Nutbrown and Clough, 2004).

\section{ETHICS STATEMENT}

This study was carried out in accordance with the recommendations of the Swedish Research Council (2017),

\section{REFERENCES}

Almqvist, L. (2006). Children's Health and Developmental Delay: Positive Functioning in Every-day Life. PhD dissertion, Örebro Studies in Psychology.

Andrade, B. F., and Tannock, R. (2013). The direct effects of inattention and hyperactivity/impulsivity on peer problems and mediating roles of prosocial and conduct problem behaviors in a community sample of children. J. Atten. Disord. 17, 670-680. doi: 10.1177/1087054712437580

Aydogan, C. (2012). Influences of Instructional and Emotional Classroom Environments and Learning Engagement on Low-Income Children's Achievement in the Prekindergarten Year. $\mathrm{PhD}$ dissertion, Vanderbilt University.

Björck-Åkesson, E., and Granlund, M. (2004). "Early intervention in Sweden-a developmental systems perspective," in A Developmental Systems Approach to Early Intervention: National and International Perspectives, ed M. Guralnick (London: Brookes Publishing), 571-591.

Bjurek, H., Gustavsson, B., Kjulin, U., and Kärrby, G. (1996). Efficiency and quality when providing public child care in Sweden. Scand. J. Educ. Res. 40, 217-238 571-591. doi: 10.1080/0031383960400303

Blair, K. S. C., Fox, L., and Lentini, R. (2010). Use of positive behavior support to address the challenging behavior of young children within a community early childhood program. Topics Early Child. Spec. Educ. 30, 68-79. doi: $10.1177 / 0271121410372676$

Campbell, S. B., Shaw, D. S., and Gilliom, M. (2000). Early externalizing behavior problems: toddlers and preschoolers at risk for later maladjustment. Dev. Psychopathol. 12, 467-488. doi: 10.1017/S0954579400003114

Casey, A. M., McWilliam, R. A., and Sims, J. (2012). Contributions of incidental teaching, developmental quotient, and peer interactions to child engagement. Infants Young Child. 25, 122-135. doi: 10.1097/IYC.0b013e3182 4 cbac 4 with written informed consent from all parents to the children participating in the study. The study was approved by the ethics vetting board in Linköping, Sweden (Dnr 2012/199-31).

\section{AUTHOR CONTRIBUTIONS}

All authors in this paper made substantial and significant contributions to this work.

MatG obtained the grant to fund the research efforts, and together with LA designed the study. MS took a large part in implementing the study. LA analyzed the quantitative data, and chiefly wrote these parts of the Method and Results sections of the manuscript. MS and MarG analyzed the qualitative data and wrote these parts of the Methods and Results. MatG and LA sketched out the Introduction and Discussion sections and MS and MarG substantially contributed to these sections, and with revising the rest of the manuscript.

All authors have approved the final version to be published and agrees to be accountable for all aspects of the work in ensuring that questions related to the accuracy or integrity of any part of the work are appropriately investigated and resolved.

\section{FUNDING}

This work was financially supported by The National Board of Health and Welfare under Grant [2011/491], as well as the Swedish Research Council for Health, Working Life and Welfare under Grant [2013/38].

Cohen, J., and Mendez, J. (2009). Emotion regulation, language ability, and the stability of preschool children's peer play behavior. Early Educ. Dev. 20, 1016-1037. doi: 10.1080/10409280903305716

Coplan, R. J., Wichmann, C., and Lagace-Seguin, D. G. (2001). Solitary-active play behavior: a marker variable for maladjustment in the preschool? J. Res. Childh. Educ. 15, 164-172. doi: 10.1080/02568540109594957

D’Souza, S., Waldie, K., Peterson, E., Underwood, E., and Morton, R. (2017). Psychometric Properties and Normative Data for the Preschool Strengths and Difficulties Questionnaire in Two-Year-Old Children. J. Abnorm. Child Psychol. 45, 345-357. doi: 10.1007/s10802-016-0176-2

de Kruif, R. E. L., and McWilliam, R. A. (1999). Multivariate relationships among developmental age, global engagement, and observed child engagement. Early Child. Res. Q. 14, 515-536. doi: 10.1016/S0885-2006(99)00028-9

Department for Education/Department of Health (2015). Special Educational Needs and Disability Code of Practice: 0 to 25 years. London: Crown Copyright.

Drabble, S. (2013). Support for children with special Educational Needs (SEN). Geneva: European Commission: Employment, Social Affairs \& Inclusion.

Drugli, M. (2014). "Psykiske vansker hos barn i førskolealder [Psychological difficulties of children in the preschool age]," in Utvikling, lek og loering $i$ Barnehagen Forskning og Praksis [Development, Play and Learning in Preschool Research or Practice], eds V. Glaser, I. Størksen, and M. Drugli (Bergen: Fagbokforlaget Vigmostad \& Bjørke AS), 234-252.

Dunst, C. J., Hamby, D., and Brookefield, J. (2007). Modeling the effects of early childhood intervention variables on parent and family well-being. J. Appl. Quant. Methods 2, 268-288.

Egger, H., and Angold, A. (2006). Common emotional and behavioral disorders in preschool children: presentation, nosology, and epidemiology. J. Child Psychol. Psychiatry 47, 313-337. doi: 10.1111/j.1469-7610.2006.01618.x

Elo, S., and Kyngäs, H. (2008). The qualitative content analysis process. J. Adv. Nurs. 62, 107-115. doi: 10.1111/j.1365-2648.2007.04569.x 
European Agency for Special Needs and Inclusive Education (2016). Inclusive Early Childhood Education: An Analysis of 32 European Examples. eds E. Bartolo, E. Bjoörck-AÅkesson, and M. Kyriazopoulou (Odense) Available online at: https://www.european-agency.org

Farran, D. C., and Son-Yarbrough, W. (2001). Title I funded preschools as a developmental context for children's play and verbal behaviors. Early Child. Res. Q. 16, 245-262. doi: 10.1016/S0885-2006(01)00100-4

Fuhs, M. W., Farran, D. C., and Nesbitt, K. T. (2013). Preschool classroom processes as predictors of children's cognitive self-regulation skills development. Sch. Psychol. Q. 28, 347-359. doi: 10.1037/spq0000031

Gardner, F., and Shaw, D. S. (2011). "Behavior problems of infancy and preschool children (0-5)," in Rutter's Child and Adolescent Psychiatry 5th Edn, eds M. Rutter, D. Bishop, D. Pine, S. Scott, J. Stevenson, E. Taylor, and A. Thapar (London: Wiley-Blackwell), 882-894.

Gillberg, C. (2010). The ESSENCE in child psychiatry: early symptomatic syndromes eliciting neurodevelopmental clinical examinations. Res. Dev. Disab. 31, 1543-1551. doi: 10.1016/j.ridd.2010.06.002

Goodman, R. (1997). The strengths and difficulties questionnaire: a research note. J. Child Psychol. Psychiatry 38, 581-586.

Goodman, R. (2001). Psychometric properties of the Strengths and Difficulties Questionnaire. J. Am. Acad. Child Adolesc. Psychiatry 40, 1337-1345. doi: 10.1097/00004583-200111000-00015

Granlund, M., Almqvist, L., Gustafsson, P., Gustafsson, B., Golsäter, M., Prozchowska-Björklund, M., et al. (2015). Tidig upptäckt - tidig insats: slutrapport [Early detection - early intervention: final report]. Jönköping: Jönköping university/CHILD.

Granlund, M., and Lillvist, A. (2015). With or without diagnosis: factors influencing participation by preschool children with mild intellectual disability in Sweden. Res. Prac. Intell. Dev. Disab. 2, 126-135. doi: 10.1080/23297018.2015.1079729

Green, B. L., Ayoub, C., Bartlett, J. D., Von Ende, A., Furrer, C., ChazanCohen, R., et al. (2014). The effect of Early Head Start on child welfare system involvement: a first look at longitudinal child maltreatment outcomes. Child. Youth Serv. Rev. 42, 127-135. doi: 10.1016/j.childyouth.2014. 03.044

Groark, C., Eidelman, S., Kaczmarek, L. A., and Maude, S. P. (2011). Early Childhood Intervention: Shaping the Future for Children With Special Needs and Their Families. Vol. 1-3. Santa Barbara, CA: Praeger/ABC-CLIO.

Gustafsson, B. M., Gustafsson, P. A., and Proczkowska-Björklund, M. (2016). The Strengths and Difficulties Questionnaire (SDQ) for preschool children - a Swedish validation. Nord. J. Psychiatry 70, 567-574. doi: 10.1080/08039488.2016.1184309

Hester, P. P., Baltodano, H. M., Hendrickson, J. M., Tonelson, S. W., Conroy, M. A., and Gable, R. A. (2004). Lessons learned from research on early intervention: what teachers can do to prevent children's behavior problems. Prevent. Sch. Failure 49, 5-10. doi: 10.3200/PSFL.49.1.5-10

Keenan, K., Shaw, D. S., Walsh, B., Delliquadri, E., and Giovannelli, J. (1997). DSM-III-R disorders in preschool children from lowincome families. J. Am. Acad. Child Adolesc. Psychiatry 36, 620-627. doi: 10.1097/00004583-199705000-00012

Lahdenperä, P. (1999). Fristående Skolors tal Om och Hantering av barn i Behov av Sav barn i Behov av Saörskilt sto?d [Freestanding Schools Speak About the Handling of Children in Need of Special Support]. Stockholm: Teacher Education in Stockholm, Department of Special education.

Lebeer, J., Struyf, E., De Maeyer, S., Wilssens, M., Timbremont, B., Denys, A., et al. (2010). Identifying special educational needs: putting a new framework for graded learning support to the test. Eur. J. Spec. Needs Educ. 25, 375-387. doi: $10.1080 / 08856257.2010 .513542$

Lillvist, A., and Granlund, M. (2010). Preschool children in need of special support: prevalence of traditional disability categories and functional difficulties. Acta Paediatr. 99, 131-134. doi: 10.1111/j.1651-2227.2009. 01494.x

McWilliam, R. A. (1991). Children's Engagement Questionnaire. Instrument. Frank Porter Graham Child Development Center, University of North Carolina, Chapel Hill, NC.

National Agency for Education (2010). Curriculum for Preschool Lpfö 98. Revised 2010. Stockholm: National Agency for Education.
National Agency for Education (2015). Beskrivande Data 2015 [Descriptive Statistics 2015]. Stockholm: National Agency for Education.

Nutbrown, C., and Clough, P. (2004). Inclusion and exclusion in the early years: conversations with European educators. Eur. J. Spec. Needs Educ. 19, 301-315. doi: 10.1080/0885625042000262479

OECD (2006). Starting Strong II: Early Childhood Education and Care. Paris: OECD.

Plueck, J., Eichelberger, I., Hautmann, C., Hanisch, C., Jaenen, N., and Doepfner, M. (2015). Effectiveness of a teacher-based indicated prevention program for preschool children with externalizing problem behavior. Prevent. Sci. 16, 233-241. doi: 10.1007/s11121-014-0487-x

Poulou, M., and Norwich, B. (2000). Teachers' perceptions of students with emotional and behavioural difficulties: severity and prevalence. Eur. J. Spec. Needs Educ. 15, 171-187. doi: 10.1080/088562500361600

Pramling Samuelsson, I., Williams, P., Sheridan, S., and Hellman, A. (2015). Swedish preschool teacher's ideas of the ideal preschool group. Int. J. Early Childh. Res. 14, 1-17. doi: 10.1177/1476718X14559233

Raspa, M. J., McWilliam, R. A., and Maher Ridley, S. (2001). Child care quality and children's engagement. Early Educ. Dev. 12, 209-224. doi: 10.1207/s15566935eed1202_3

Raver, C. C., Jones, S. M., Li-Grining, C., Zhai, F., Metzger, M. W., and Solomon, B. (2009). Targeting children's behavior problems in preschool classrooms: a cluster-randomized controlled trial. J. Consult. Clin. Psychol. 77, 302-316. doi: $10.1037 / \mathrm{a} 0015302$

Swedish Research Council (2017). Good Research Practice. Stockholm: Swedish Research Council.

Rimm-Kaufman, S. E., Pianta, R. C., and Cox, M. J. (2000). Teachers' judgements of problems in the transition to kindergarten. Early Child. Res. Q. 15, 147-166. doi: 10.1016/S0885-2006(00)00049-1

Sandberg, A., Lillvist, A., Eriksson, L., Björck-Åkesson, E., and Granlund, M. (2010). "Special Support" in Preschools in Sweden: Preschool staff's definition of the construct. Int. J. Disab. Dev. Educ. 57, 43-57. doi: 10.1080/10349120903537830

Sandberg, A., Norling, M., and Lillvist, A. (2009). Teachers' view of educational support to children in need of special support. Int. J. Early Childh. Spec. Educ. 1, 102-116. doi: 10.3109/09638288.2015.1021021

Sheridan, S., Williams, P., and Pramling Samuelsson, I. (2014). Group size and organisational conditions for children's learning in preschool: a teacher perspective. Educ. Res. 56, 379-397. doi: 10.1080/00131881. 2014.965562

Sheridan, S., Williams, P., Sandberg, A., and Vuorinen, T. (2011). Preschool teaching in Sweden - a profession in change. Educ. Res. 53, 415-437. doi: $10.1080 / 00131881.2011 .625153$

Sjöman, M., Granlund, M., and Almqvist, L. (2016). Interaction processes as a mediating factor between children's externalized behaviour difficulties and engagement in preschool. Early Child Dev. Care 186, 1649-1663. doi: $10.1080 / 03004430.2015 .1121251$

Skalická, V., Belsky, J., Stenseng, F., and Wichstrøm, L. (2015). Reciprocal relations between student-teacher relationship and children's behavioral problems: moderation by child-care group size. Child Dev. 86, 1557-1570. doi: $10.1111 /$ cdev. 12400

Snell, M. E., Berlin, R. A., Voorhees, M. D., Stanton-Chapman, T. L., and Haddens, S. (2012). A survey of preschool staff concerning problem behavior and its prevention in Head Start Classrooms. J. Posit. Behav. Interv. 14, 98-107. doi: $10.1177 / 1098300711416818$

Spivak, A. L., and Farran, D. C. (2016). Predicting first graders' social competence from their preschool classroom interpersonal context. Early Educ. Dev. 27, 735-750. doi: 10.1080/10409289.2016.1138825

Swedish Schools Inspectorate (2017a). Förskolans Arbete Med Flerspråkliga Barns Språkutveckling. [Preschools work with multi linguistic children]. Stockholm: Schools Inspectorate.

Swedish Schools Inspectorate (2017b). Förskolans Arbete Med Barn i Behov av Särskilst Stöd. [Preschools work with children in need of special support]. Stockholm: Schools Inspectorate.

Swedish National Institute of Public Health (2009). Child Day Care Center or Home Care for Children 12-40 Months of Age - What is Best for the Child? A Systematic Review. Stockholm: Strömberg. 
Svensson, B., and Janson, S. (2008). Suspected Child Maltreatment: preschool staff in a conflict of loyalty. Early Childh. Educ. 36, 25-31. doi: 10.1007/s10643-008-0248-1

Taggart, B., Sammons, P., Smees, R., Sylva, K., Melhuish, E., Siraj-Blatchford, I., et al. (2006). Early Identification of Special Educational Needs and the Definition of "At Risk": The Early Years Transition and Special Educational Needs (EYTSEN) Project. Br. J. Spec. Educ. 33, 40-45. doi: 10.1111/j.1467-8578.2006.00410.x

Teddlie, C., and Tashakkori, A. (2012). Common "core" characteristics of mixed methods research. Am. Behav. Sci. 56, 774-777. doi: $10.1177 / 0002764211433795$

Tegenfeldt, T., and Hellgren, L. (2009). Förskolans Metoder för Att Förebygga Psykisk Ohälsa. En Nationell Inventering. [Methods in Preschool to Prevent Mental Illness. a national survey]. Stockholm: National Board of Health and Welfare.
Wood, E. A. (2013). Free choice and free play in early childhood education: troubling the discourse. Int. J. Early Years Educ. 22, 4-18. doi: $10.1080 / 09669760.2013 .830562$

Conflict of Interest Statement: The authors declare that the research was conducted in the absence of any commercial or financial relationships that could be construed as a potential conflict of interest.

Copyright (C) 2018 Almqvist, Sjöman, Golsäter and Granlund. This is an open-access article distributed under the terms of the Creative Commons Attribution License (CC $B Y)$. The use, distribution or reproduction in other forums is permitted, provided the original author(s) and the copyright owner are credited and that the original publication in this journal is cited, in accordance with accepted academic practice. No use, distribution or reproduction is permitted which does not comply with these terms. 